\title{
Introduction
}

\section{Political Disorder and Decay}

Yong J. Yoon

This introduction will serve as a roadmap to this book and should help to contextualize the articles.

We began planning to publish Individualism and Political Disorder in 2012. The title suggests the book's theme, which contrasts with F.A. Hayek's theme and the title of his book, Individualism and Economic Order. The chapters in the book are papers written by Buchanan, singly or jointly with Yoon, after the publication of his collected work volumes (1999-2001). Inevitably, you will hear Buchanan's voice on his basic philosophy in political economy. The papers are listed in chronological order and they have all been published in academic journals or books, except the last one.

A theme emerges naturally from these articles: that collective actions work differently from the way the market works. This difference requires a different mode of thinking and tools of analysis than those used for the market. Buchanan emphasized this point early in his career in 1954. The market order achieved by individual self-interest is not our main focus, but it is discussed in part in Chapter 10 ('Public Choice and the Extent of the Market'). We invoke the Adam Smith theorem on economic progress: the economy grows by expanding the extent of the market that allows for more division of labor and specializations. Opening the economy internally and externally would achieve this. In this book, we examine how the same selfinterest is exercised in political exchanges, which are much more complex than exchanges in the market.

Three topics are developed gradually which interact in this book. These sub-themes help us to analyze the main theme: the tragedy of the political commons. The first of the three topics is a theory of rules (covered in Chapters 2 and 3). The second topic is the institution of majority rule, of which different aspects are covered in Chapters 1, 9, and 11. The third topic is the commons problem or the 'tragedy of the commons', a term coined by Garrett Hardin. Chapter 5 discusses the symmetric tragedies of the commons and anti-commons. Briefly, the tragedy of the commons states that the open access to a resource results in the dissipation of value of the resource from over-usage on the part of all users who behave in accordance with individual rationality and self-interest. The symmetric tragedy of the anti-commons arises when several property-right holders have exclusion (veto) rights without usage rights, resulting in the underutilization of the resources.

Typically, the tragedy of the commons is studied by assuming a monolithic decision maker. In our study of politics in this book, the decision maker is the coalition that wins a majority vote. Each majority coalition formed is a decision maker with access to the common resource - in this case, the tax base.

Democracy is sometimes identified with the institution of majority rule. Yet the nature of majority rule is often poorly understood. The book illuminates three points much ignored by 
public choice scholars. For instance, alternatives for collective decisions are treated as if they are arrived at exogenously. Chapter 1 notes that alternatives for collective actions are endogenously formed by the emerging majority coalitions. Chapter 9 introduces preference intensity in voting and analyzes the standard model of three voters and three alternatives. Under this assumption, all voters behave strategically instead of voting according to their primitive preferences. Chapter 11 makes an obvious yet puzzling point. Voters in collective actions end up choosing a vector rather than a scalar, because a choice in voting generates a flow of net income for each person in the policy. A voter has to form a preference over the vectors. A numerical illustration would be helpful.

Consider three persons (I, II, and III) who share a dormitory room. They want to paint the wall with a color, Red (R), Blue (B), or Yellow (Y). Each person receives a net benefit flow from the colors as shown by the matrix below:

$\begin{array}{llll} & \mathrm{R} & \mathrm{B} & \mathrm{Y} \\ \text { I: } & (1.5, & 1.5, & 0) \\ \text { II: } & (1.5, & 0, & 1) \\ \text { III: } & (1.5, & 3, & 3)\end{array}$

That is, Person I receives 1.5 units from Red, 1.5 units from Blue, and zero units from Yellow, and so on. Individual evaluation based on narrow personal consumption says Person I is indifferent between Red and Blue, but prefers either one to Yellow. For each person, their individual evaluation is as follows, where the notation ' $\sim$ ' indicates 'indifferent between' and '>' indicates 'preferred to':

$\begin{array}{ll}\text { I: } & \mathrm{R} \sim \mathrm{B}>\mathrm{Y} \\ \text { II: } & \mathrm{R}>\mathrm{Y}>\mathrm{B} \\ \text { III: } & \mathrm{B} \sim \mathrm{Y}>\mathrm{R}\end{array}$

Voters may evaluate the distributions in a way different from their narrow personal consumption. Consider the following voters' evaluation of the vectors: in addition to personal consumption, Person I is also concerned with 'fairness', and Person III is also concerned with 'efficiency'. Person II is concerned with personal consumption only. Efficiency here means to maximize the aggregate units in the community of the three persons. Voting results are by simple majority rule with pairwise comparisons. By simple arithmetic we can compare the following two cases.

Case 1: They vote according to narrow personal consumption. The voting result will be:

$\mathrm{R}$ is the winner, with probability $1 / 2$;

$\mathrm{B}$ is the winner, with probability $1 / 4$; and

Cycling majority, with probability $1 / 4$.

Case 2: In addition to personal consumption, Person I is concerned with fairness, and Person III is concerned with efficiency. Then, Person I evaluates R ahead of B, and Person III evaluates B ahead of Y. Their preference orderings are: 


\section{I: $\quad \mathrm{R}>\mathrm{B}>\mathrm{Y}$ \\ II: $\mathrm{R}>\mathrm{Y}>\mathrm{B}$ \\ III: $\mathrm{B}>\mathrm{Y}>\mathrm{R}$}

The voting outcome is ' $R$ '. This exercise indicates that the voting result depends on the voters' evaluation of the vector rather than narrow personal consumption. Voters may consider tradeoffs between personal consumption and other aspects of the distributions.

With the analytics (logical analysis) for majority rule and the commons problems, we apply majoritarian democracy to the fiscal problems in which the tax base is the commons. The theory developed in this book predicts a tragedy of the fiscal commons. The rent-seeking and benefit-seeking activities will exhaust potential economic surplus created by the voters themselves. The fiscal tragedy of the commons, under the majoritarian institution, is treated in the following chapters: Chapter 7 ('Universalism through Common Access: An Alternative Model of Distributive Majoritarian Politics'); Chapter 8 ('Majoritarian Exploitation of the Fiscal Commons: General Taxes-Differential Transfers'); Chapter 12 ('The Costs of Collectivization, Per Se'); and Chapter 13 ('Institutional Sources of America's Fiscal Tragedy').

In Chapter 13, Buchanan describes the problem, analyzes it, and proffers solutions. American fiscal institutions are dysfunctional; the tragedy is chronic overspending and the difficulty in controlling it. Buchanan notes three institutional sources of the chronic fiscal deficit. First is the undermining of the classical fiscal norm of a balanced budget in the postKeynesian period. The wisdom of a balanced budget is forgotten and even considered to be an outdated practice and theory. Second is the asymmetric two sides of the fiscal budget: taxation and spending. By constitutional requirements, taxation is more general and universal. Spending is discriminatory. This invites interest groups to engage in discriminatory spending. Third is the priority of spending to taxation.

Buchanan suggests reforms that constitutions could implement. For the first problem, impose a balanced budget. For the second, impose reduced distribution of spending, perhaps by requiring the GINI index of spending to be equal to that of taxation. (This point is based on the generality principle which is more fully treated in Buchanan and Congleton, 1998.) For the third problem, impose a tax limit before engaging in a budgetary process.

As exposited in The Calculus of Consent (1962), the solution to political disorder that Buchanan offers is a constitutional convention in which each person has the incentive to choose more efficient rules. Each voter will see and choose from behind the veil of uncertainty, ignorant of their future positions in the society. This was the solution offered during the optimistic era (periods) of Buchanan and many other intellectuals in the late 1950s and early 1960s. Buchanan might be more pessimistic now about the state of political order and the likelihood of correcting it. This is not necessarily because the current problems are worse. Perhaps, he might think that the intellectual and scientific ideas are slow in influencing society and the general population. As we read in an interview published in Region magazine, he was quite affected by the 1960s. He was upset by the turmoil and anarchy on campuses and the behavior of the Academy, faculty, and administration. Thus, when he came to Blacksburg, Virginia, he 'began searching around for some space and privacy'. ${ }^{1}$ Nevertheless, the most accurate characterization was expressed by Buchanan himself. He has been pessimistic ex ante, but became optimistic ex post. 
What we demonstrate in the book is that democracy without rules to control self-interest leads to political disorder. Fukuyama (2014) makes a similar point in his new book: too much democracy in American political institutions leads to political decay. Fukuyama considers extensively the interactions between the executive, judiciary, and legislative branches of the government. ${ }^{2}$ Interest groups grow and they work to make any reform difficult by preventing such laws from passing in the legislature. These interest groups also work as a vetocracy, much like the anti-commons introduced in Chapter 5 on symmetric tragedies: commons and anti-commons. One suggestion for mitigating the effects of anti-commons is to reduce the number of veto holders.

As Buchanan and Fukuyama argue, the solution to political disorder and political decay depends on whether we can agree to a better rule. It is generally understood that the human species has the capacity to invent and follow rules, so I am tempted to discuss the psychological aspects of rules. For this discussion, I will further elaborate on two chapters in the book. Personal rules are discussed in Chapter 2: 'Rationality as Prudence: Another Reason for Rules', and social rules are discussed in Chapter 3: 'The Efficacy of Arbitrary Rules'.

We model human choice behavior as if there is no command-control center. It consists of Ainslie's (1992) homunculi, homo economicus being one of them, separate little persons with individual minds. The assumption is consistent with Hume's theory of mind and Gautama Buddha's even earlier theory of Anatma (no self). The mind faces complex problems from its environment. Without constraints, the mind faces a commons problem from the multidimensional complexity, as is discussed in Chapter 2. Without considering the opportunity costs, each dimension can lead to satiation. By imposing a rule which imposes constraints on actions, we create a shadow price for each dimension of activity. Consider several activities, for example, reading the newspaper, playing with the dog, helping your spouse, and vacationing. Without rules, our behavior tends to meliorate, equalizing average utility among different activities, while rule-bound behavior tends to maximize by equalizing marginal utility.

To maximize the result (utility function is not introduced yet), regardless of the utility or objective, the mind as a resource will be maximally utilized by imposing a restraint. But, such restraints will make us feel frustrated. We have to stop vacationing when we feel we could get more net benefit from more of it. Frustration with each dimension is a necessary condition for maximizing the resources of the mind. Economists tend to believe that the more choices there are, the better choices you will make. However, psychologists (Iyengar and Lepper, 2000) report an interesting observation. 'When people were given a larger array of choices - thirty rather than six gourmet chocolates from which to choose, they were either unable to choose or, if they choose, they were less satisfied with it.'

Thus, what we call 'prudence' in our behavior, and the doctrine of the mean (中庸: Zhōng $y \bar{o} n g$ ) in Confucian philosophy, suggests an insight into the mind without a central coordinator. The insight we learn from human choice behavior has applications to society as well. An arbitrary rule can be efficient when compared to no rule. No rule here is equivalent to direct democracy, or too much democracy in Fukuyama.

Going back to the dimensionality of the mind, psychologist William James' (1890) description of infant minds is suggestive. The world which babies enter is 'one great blooming, buzzing confusion'. The infant mind sees confusion in the multi-dimensional complexity. The emergence of identity as one grows up is a device for organizing the mind by imposing 
restraints. Thus, our identity or self is not natural but an artifact. Our identity is like a bookkeeping account which is instrumental in maximizing the resources of the mind. Or our identity is a device to reduce resource wastage and the complexity of reality by distorting it somewhat.

\section{Acknowledgements}

An earlier version of the introductory chapter was first presented at Buchanan's alma mater, Middle Tennessee State University, on October 2, 2014. I acknowledge the summer support (2014) provided by the Center for Study of Public Choice, under the direction of Alex Tabarrok. Also acknowledged is the support promised by the Interdisciplinary Center for Economic Science under the direction of Daniel Houser. Both centers are at George Mason University. I acknowledge the editing help from Alan Sturmer of Edward Elgar and Gary Corseri.

\section{Notes}

1. Federal Reserve Bank of Minneapolis (1995).

2. Fukuyama does not specify the political process.

\section{References}

Ainslie, G. (1992), Picoeconomics: The Strategic Interaction of Successive Motivational States within the Person, New York: Cambridge University Press.

Buchanan, J.M. (1954), 'Individual choice in voting and the market', Journal of Political Economy, 62 (4), August, 334-43.

Buchanan, J.M. and G. Tullock (1962), The Calculus of Consent: Logical Foundation of Constitutional Democracy, Ann Arbor, MA: University of Michigan Press.

Buchanan, J. and R. Congleton (1998), Politics by Principle, Not Interest: Towards Nondiscriminatory Democracy, Cambridge, UK: Cambridge University Press.

Federal Reserve Bank of Minneapolis (1995), 'Interview with James Buchanan', Region, 9, September, https://www. minneapolisfed.org/publications/the-region/interview-with-james-buchanan [last accessed 26 June 2015]

Fukuyama, F. (2014), Political Order and Political Decay: From the Industrial Revolution to the Globalisation of Democracy, London, UK: Profile Books Ltd.

Iyengar, S. and M. Lepper (2000), 'When choice is demotivating: Can one desire too much of a good thing?', Journal of Personality and Social Psychology, 79 (6), 995-1006. 
Yong J. Yoon - 9781784710583 